\title{
20. THERMAL MODELING FOR HOLE 735B ${ }^{1}$
}

\author{
R. P. Von Herzen ${ }^{2}$ and J. H. Scott ${ }^{3}$
}

\begin{abstract}
Two temperature logs subsequent to the drilling of the 500-m-deep Hole 735B on the flank of the Atlantis-II Fracture Zone in the southwest Indian Ocean are used to determine the equilibrium temperature profile beneath the seafloor. The overall equilibrium temperature gradient with depth is negative at the surface, then changes to a positive gradient at about $300 \mathrm{~m}$, and gradually increases to the bottom of the hole. Positive excursions of the temperature profile are centered at depths of about 30,190, and $260 \mathrm{~m}$ below the seafloor (mbsf). The data are interpreted using two different models: (1) advection of seawater into permeable zones in the upper $400 \mathrm{~m}$ beneath the seafloor and (2) warming by conduction from the surface since the last glacial maximum. The heat flow implied by the temperature profile in the deepest part of the hole is low $\left(<30 \mathrm{~mW} \mathrm{~m}^{-2}\right)$, but even at this depth the temperature gradient is probably not representative of the heat flux from below.
\end{abstract}

\section{INTRODUCTION}

At Site 735 , a 500 -m-deep hole was drilled into a relatively flat, shallow gabbro ridge over a period of 17 days. Immediately following the drilling and coring, Hole 735B was logged by lowering tools through the drill pipe, over a period of about 6 days. Here, we describe and interpret the data from two temperature logs made in the hole during the logging.

Site 735 is located near the crest of the ridge bordering the eastern flank of the Atlantis-II Fracture Zone (Fig. 1). The ridge is aligned nearly north-south like the fracture zone valley, and its flanks descend steeply (up to $45^{\circ}$ ) to both the east and west within a few kilometers laterally of the shallow seafloor depth $(730 \mathrm{~m})$ at Hole $735 \mathrm{~B}$. The nearly flat portion of the ridge crest at Site 735 extends 3 to $4 \mathrm{~km}$ east-west and about $10 \mathrm{~km}$ north-south, based on the SeaBeam survey data (Dick et al., this volume); Hole 735B is located in the southwest corner of this crustal platform, about 1 to $1.5 \mathrm{~km}$ from the upper part of the steep western flank. The morphology of the ridge crest at Site 735 suggests that it was eroded at sea level and subsequently subsided to its present depth.

Based on the plate geometry and modeling of magnetic anomalies (Dick et al., this volume), the seafloor at Site 735 was created about 10 to $12 \mathrm{Ma}$ at the spreading ridge segment to the north. The unusual type of rock drilled in Hole 735B may be a result of an initially thin crustal section, as found in and near other fracture zones (Cormier et al., 1984), and/or the result of removal of the upper crustal section by erosion. The ridge on which Site 735 is located seems analogous to the flanking ridges of other transforms where ultrabasic rocks have been sampled (e.g., Bonatti and Hamlyn, 1980), implying uplift of the entire crustal section by several kilometers within a few million years after formation, subsequently followed by a smaller amount of subsidence. Here, we do not include modeling of the thermal effects of uplift and subsidence, because their timing and mechanisms are obscure, and in any case the effects are likely to be small because of the long time scales involved.

\footnotetext{
${ }^{1}$ Von Herzen, R. P., Robinson, P. T., et al., 1991. Proc. ODP, Sci. Results, 118: College Station, TX (Ocean Drilling Program).

${ }^{2}$ Woods Hole Oceanographic Institution, Woods Hole, MA 02543.

${ }^{3}$ Lakewood, CO 80228.
}

\section{TEMPERATURE DATA AND ANALYSIS}

The instrumentation and acquisition of the temperature logs in Hole 735B were described in detail in the Leg 118 Initial Reports volume (Shipboard Scientific Party, 1989, pp. 165-168). Two logs of high quality data were made about 1.9 and 3.4 days after completion of drilling. Both showed a small negative temperature gradient with depth over most of the hole (Fig. 2), and the temperatures obtained with the second log averaged about $1.5^{\circ} \mathrm{C}$ cooler than the first. The cooling of the entire hole after drilling reflects the effects of the relatively warm $\left(\sim 20^{\circ} \mathrm{C}\right)$ surface water pumped down the hole during drilling operations and indicates that equilibrium temperature of the shallowest $500 \mathrm{~m}$ of rock is everywhere less than about $20^{\circ} \mathrm{C}$, the approximate temperature of the surface water, over the depth of the hole.

The temperatures measured in the hole are a combination of the steady-state equilibrium temperature $\left(T_{e}\right)$ and the transient temperature disturbance $(T)$ caused by drilling, both functions of depth. We remove $T$ analytically by using the simplified model of radial heat conduction in a borehole, originally derived by Bullard (1947), given as

$$
T=(Q / 4 \pi K) \log \left[1+t_{d} / t\right]
$$

The parameters in this equation, which vary with depth in the hole, are defined as

$Q=$ heat influx per unit length of borehole wall per unit time during drilling and circulation,

$K=$ thermal conductivity of rock,

$t_{d}=$ total drilling and circulation time, and

$t=$ time between measurement and cessation of drilling and circulation.

Equation 1 is valid for small values of the dimensionless parameter combination $a^{2} / 4 \alpha t$, where $a$ is the hole radius and $\alpha$ is the thermal diffusivity of the surrounding rock. For $\mathrm{a}=$ $0.12 \mathrm{~m}$ and $\alpha=8.10^{-7} \mathrm{~m}^{2} \mathrm{~s}^{-1}$ (see below), the value of this parameter set is less than 0.03 for $t>1.9$ days, the earliest logging time. $Q$ is also assumed to be constant over the period of drilling, which, although probably not strictly true, is considered a sufficient approximation because the extrapolations to equilibrium temperatures are relatively insensitive to 


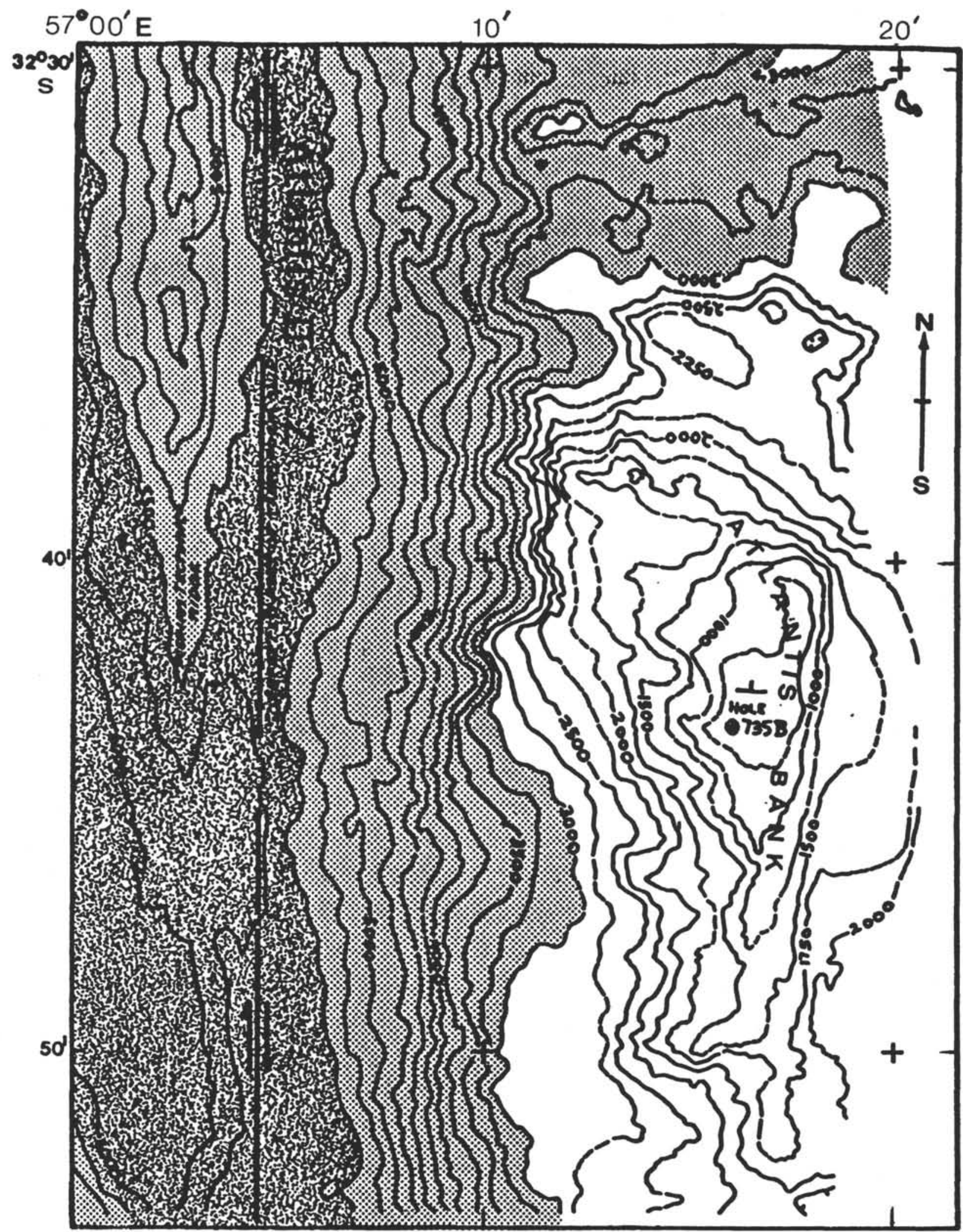

Figure 1. Seafloor depth contour map ( $250-\mathrm{m}$ contour interval) in the vicinity of Site 735 (after Dick et al., this volume). Hole $735 \mathrm{~B}$ is located near the southwest corner of a relatively flat bench with dimensions about $4 \mathrm{~km}$ east-west and $9 \mathrm{~km}$ north-south. 


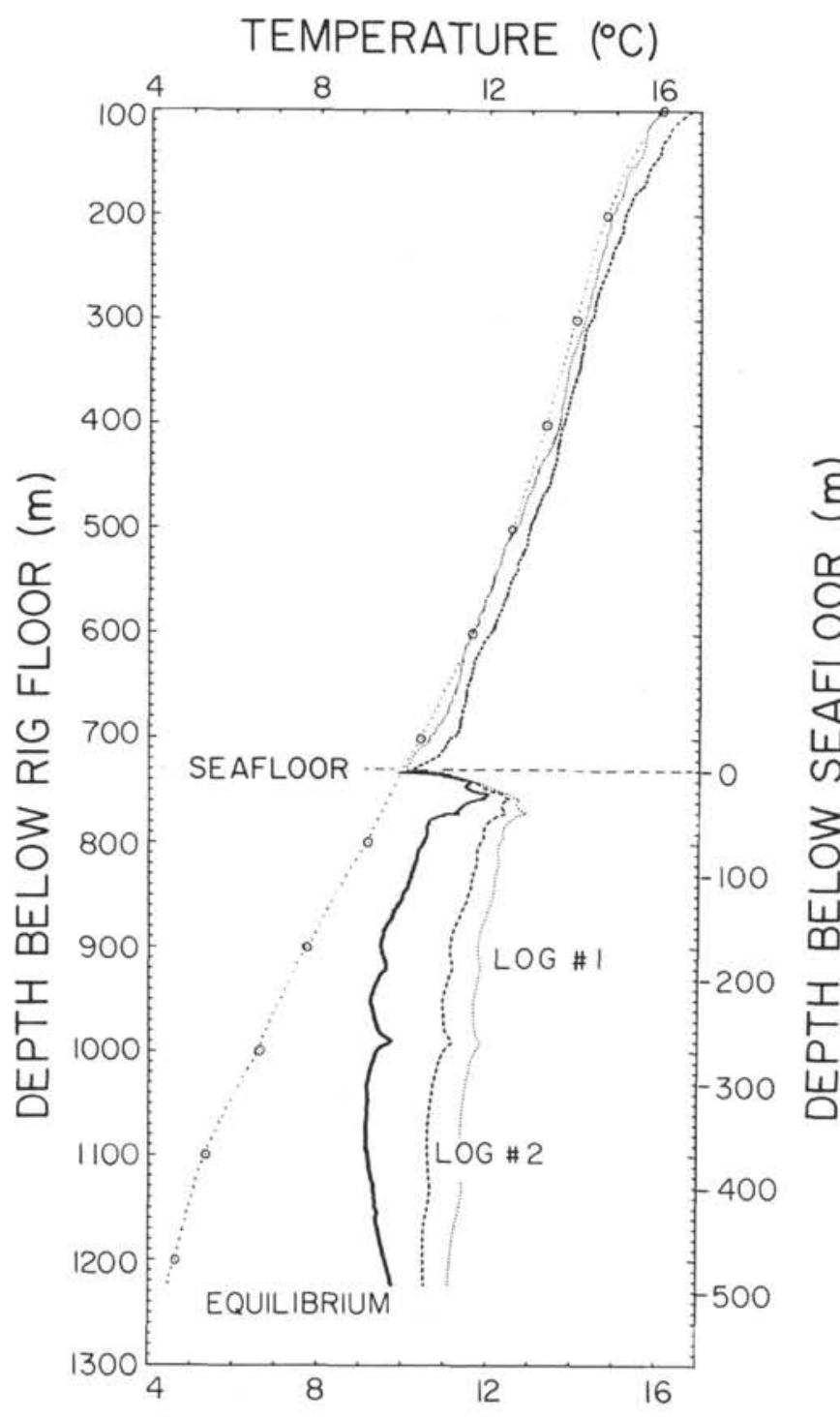

Figure 2. Temperature vs, depth measured at and near Site 735. The closely dotted curve is the temperature profile measured in the pipe and in Hole 735B about 1.9 days after completion of drilling, and the dashed curve is a similar log measured about 3.4 days after drilling. The solid curve is the calculated equilibrium temperature profile in the hole derived from these logs (see text). The widely dotted curve with circled points is the nearby ocean temperature profile $\left(33^{\circ} 58^{\prime} \mathrm{S}\right.$, $57^{\circ} 02^{\prime} \mathrm{E}$ ) measured on 16 May 1984 with CTD instrumentation (courtesy of National Geophysical Data Center).

variation in $Q$, and the relatively small equilibrium temperature gradients suggest that $Q$ would not be expected to vary much during the drilling of the hole. With at least two temperature measurements (logs) at known times, and known drilling times $t_{d}, T$ is removed by extrapolating the measured temperatures linearly to zero on the $\log \left[1+t_{d} / t\right]$ axis.

The resulting equilibrium hole temperatures, given as the heavy curve below the seafloor in Figure 2, show that the overall equilibrium temperature gradient with depth is negative in the uppermost $300 \mathrm{~m}$ or so of the hole, turning around to positive values below that depth. Significant positive excursions from a smooth temperature vs. depth curve are seen at depths of 0 to $50 \mathrm{mbsf}$, and also are centered at about 190 and 260 mbsf. It seems likely that these are depths at which zones of higher permeability rock intersect the hole, into which significant amounts of warmer water were forced during drilling, such that conduction theory no longer applies. The complex signature of the shallowest anomaly may also have been affected by pumping of some fluid into the hole by the logging tools exiting from the pipe in this region. It is not clear whether the deeper temperature anomalies represent relatively thin $(<10 \mathrm{~m})$ permeable zones centered at the maximum anomaly, with broadening of the anomaly up and down the hole caused by backflow into the hole after drilling, or whether the anomalous permeability is distributed over zones $50 \mathrm{~m}$ or so thick, with a maximum value of permeability at the depth of the largest temperature anomaly.

Figure 2 shows that the temperatures in the drill pipe above the seafloor at the logging times were close to those measured in the nearby ocean. The slightly higher temperatures measured during logging may reflect the residual effects of surface seawater pumped down the pipe previous to the temperature logs. However, note that the second log appears more anomalous with respect to ocean temperatures, which would not be the case if the differences were primarily the result of pumping down warmer surface seawater during drilling. The seawater temperature gradient below the seafloor depth of Hole 735B is also negative, the effects of which (considering the surrounding steep topography) will tend to counteract the heat flux from below.

In the following, we describe calculations from conductive models in which we attempt to model the overall equilibrium temperature gradient deduced for Hole 735B.

\section{MODELING}

\section{Model 1: Two-Dimensional Conduction Simulation of Advection}

Site 735 is located near the crest of a north-south trending ridge on the east side of the Atlantis-II Fracture Zone. Although the depth contours around the site are complex in detail, a two-dimensional (2-D) representation of the topography should give a first approximation to its expected effects. Therefore, one of our preliminary thermal models uses the 2-D finite-element algorithm and code developed by Lee and Henyey (1974) for such problems. This model allows for arbitrary 2-D topography across the upper surface and arbitrary surface temperatures for each element. The bottom boundary condition is uniform heat flow, and no heat is conducted horizontally through the vertical sides of the model. Thermal conductivity may be specified for various regions (contiguous finite elements) of the model. The vertical grid size is varied systematically from closely spaced at the top, to widely spaced at the bottom, of the models.

We used the SeaBeam-generated bathymetry contours to establish the width and configuration of the upper surface of the model (Fig. 3). We modeled the 2-D topography of an east-west section passing through Hole $735 \mathrm{~B}$ with a total width of about $38 \mathrm{~km}$ between the floor of the fracture zone to the west and the lowest point of the next valley to the east. These end-point locations were chosen for symmetry in the topography and, presumably, the heat flow as well, if it is topographically controlled. The upper surface configuration was obtained directly from the SeaBeam depth contours intersected by the east-west profile through Hole 735B; the topographic extremes, from the shallowest point near Hole $735 \mathrm{~B}$ to the fracture zone valley axis, range over $5 \mathrm{~km}$ in elevation difference. The width of element columns was variable, determined primarily by the topographic slopes, i.e., columns were more closely spaced on steep slopes, where 


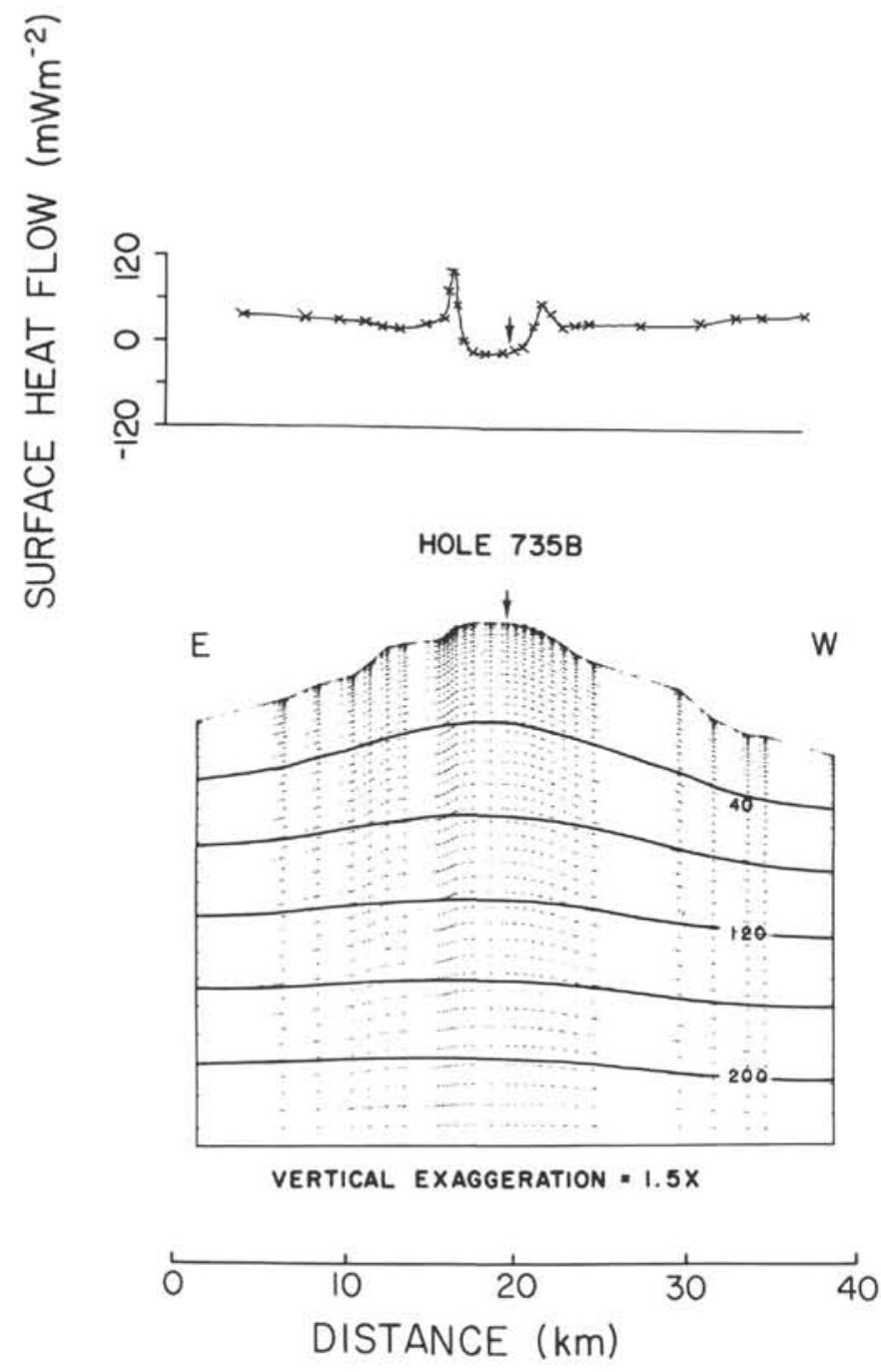

Figure 3. Lower panel shows 2-D topography and finite-element model gridding scheme of an east-west section through Hole 735B (Fig. 1). Upper panel shows surface heat flux for the upper structure modeled in Figure 4 (Model 2R7) with a uniform heat flux of $30 \mathrm{~mW}$ $\mathrm{m}^{-2}$ into the base of the model.

surface temperatures are more variable, and in proximity to Hole $735 \mathrm{~B}$. The locations of columns on the section were determined primarily by slope breaks.

The total depth of the models was chosen about $20 \mathrm{~km}$ below the highest topography, a compromise between resolution in surface temperature gradient (heat flow) and avoiding distortions that might be caused by placing the bottom surface with uniform heat flow at too shallow depths. For this choice and the use of 49 variably spaced rows, the thickness of the uppermost row was about $14 \mathrm{~m}$, and the lowermost slightly more than $1 \mathrm{~km}$. The water temperature on the upper boundary varied over about $10^{\circ} \mathrm{C}$ from the shallowest to deepest points, with most of that variation occurring over the uppermost $1 \mathrm{~km}$ of the model.

We quickly found (see "Results of Model 1"' below) that models having uniform conductivity could not reproduce the negative equilibrium temperature gradient found for the upper part of Hole 735B. However, the analogous negative gradient in seawater at the same depths suggested a model with horizontal seawater percolation into the ridge. We simulated such permeable layers having water advection by assigning layers or regions with very high conductivity (100 times the regional value), and using forward modeling by iterations of trial models to fit the observed temperatures. We used only one or two layers of high conductivity over the $500-\mathrm{m}$-depth interval of Hole $735 \mathrm{~B}$ to fit the general equilibrium temperature profile. Obviously, more layers might be used to fit the temperature profile to higher fidelity, although the modeling of lateral advection by high-conductivity layers is only an approximate physical analog, and in any case, vertical resolution decreases with depth because of the vertical gridding scheme.

\section{Results of Model 1}

Our primary objective for modeling was to simulate as closely as possible the observed equilibrium temperature gradient in Hole $735 \mathrm{~B}$, consistent with other data from the hole and with reasonable geological assumptions. Because the thermal conductivities measured for samples recovered from Hole 735B were relatively uniform over the entire depth range (Shipboard Scientific Party, 1989), our first attempt was a conductive model having uniform conductivity throughout of $2.20 \mathrm{~W} \mathrm{~m}^{-1} \mathrm{~K}^{-1}$, subject to the upper boundary temperatures imposed by seawater, as discussed above. The laterally uniform upward heat flux through the base of the model was varied, with the constraint that the positive equilibrium gradient deduced for the lowermost 50 to $100 \mathrm{~m}$ of Hole $735 \mathrm{~B}$ implies a heat flux of only about 15 to $20 \mathrm{~mW} \mathrm{~m}^{-2}$.

The results of this initial modeling (Fig. 4) show that the temperature gradients are positive for all basal heat flows greater than about $10 \mathrm{~mW} \mathrm{~m}^{-2}$ and are nearly linear over the depth of Hole 735B. A basal heat flux of $10 \mathrm{~mW} \mathrm{~m}^{-2}$ produces nearly isothermal conditions over the upper $500 \mathrm{~m}$, or in other words, the boundary temperature structure appears approximately equivalent to a negative (downward) basal heat flux of
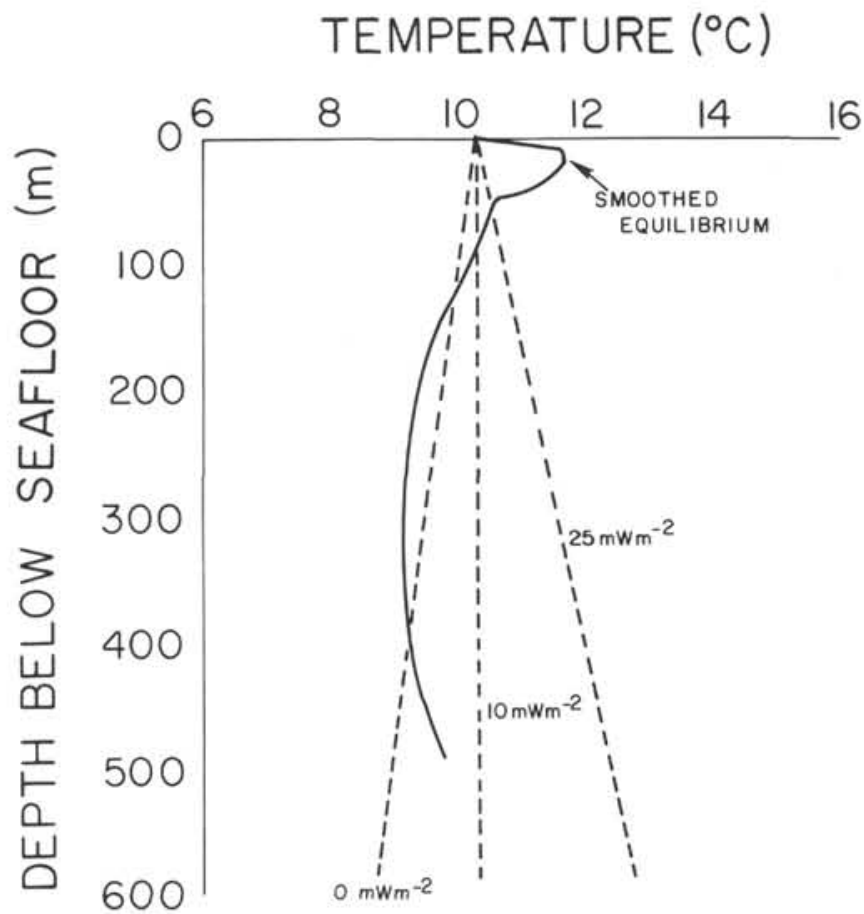

Figure 4. Temperature vs. depth profile for Hole 735B showing uniformly conducting models (dashed curves) with basal heat flows of 0,10 , and $25 \mathrm{~mW} \mathrm{~m}^{-2}$ for a 2-D boundary (Fig. 3) subject to ocean temperatures (Fig. 2). Profile of smoothed equilibrium temperature from logging is shown as solid curve. 
about $10 \mathrm{~mW} \mathrm{~m}^{-2}$ at the location of Hole 735B. A basal heat flux of zero produces a negative gradient, although less than the negative gradient in the seawater by approximately a factor of 4 as a result of the boundary geometry. Of course, a model with zero heat flux cannot reproduce the positive temperature gradient in the lower part of Hole 735B, because the boundary temperature gradient is negative everywhere with depth; the positive gradients deduced for the lower part of the hole must result from upward heat flux beneath the site. Therefore, we conclude that uniformly conductive models cannot account for the temperature structure at Site 735, regardless of the basal heat flux.

A modified model incorporates enhanced thermal interaction of at least the upper several hundred meters of the rock at Site 735 with the surrounding seawater to produce the negative temperature gradient, with decreasing coupling at greater depths as evidenced by the change in sign of the temperature gradient there. A possible mechanism for enhanced thermal coupling is lateral fluid advection of seawater into rock having significant porosity and permeability. From the logging results in Hole 735B (Goldberg et al., this volume), the overall (corrected) porosity ranges from about $3 \%$ to $8 \%$ in the depth ranges of 0 to 170 and 270 to $360 \mathrm{mbsf}$ at this site, with a few thin zones up to $20 \%$ to $25 \%$, and decreases on the order of $1 \%$ to $4 \%$ for other depth ranges. The fluid permeability tests using a borehole packer (Becker, this volume) gave permeabilities of about $10^{-14} \mathrm{~m}^{2}$ in the upper $300 \mathrm{~m}$, decreasing by about 1.5 to 2 orders of magnitude at greater depths.

Therefore, one may infer that the physical properties of the rock would allow for significant advection of interstitial fluid in the upper 200 to $300 \mathrm{~m}$ at Site 735 . However, the driving mechanism for such advection is more problematical. Thermal instability, the usual mechanism thought responsible for convection of pore water in ocean crust, is absent at this site because of the generally negative thermal gradient. Furthermore, the advection required is primarily lateral, rather than vertical, to produce the negative temperature gradient deduced for the upper parts of Hole 735B. It seems possible that tidal or other dynamic oceanographic effects on the ridge drilled at Site 735 could force slow advection of pore waters within it, but it is beyond the scope of this study to evaluate quantitatively the possibilities of driving forces for such advection.

We simulate the thermal effects of advection by assigning high values of thermal conductivity (100 times the regional value) to subhorizontal layers in our conduction model. Although such high values of thermal conductivity are physically unrealistic, they have a similar thermal effect to the horizontal advection being modeled. Effectively, the high-conductivity layers are isothermal and most of the heat transfer is focused through them, rather than through the adjacent, much lower conductivity layers above or below. An aquifer flowing horizontally at sufficient rate should have a similar behavior, primarily transferring vertical heat flux (from above or below) to the sides.

We have evaluated some simple models of this type (Fig. 5) with either one or two high-conductivity $(K)$ layers sandwiched between normally conductive layers. The layer depths and thicknesses were varied iteratively to arrive at solutions that closely approximated the equilibrium temperature structure in Hole 735B (Fig. 6). A model with a single high- $K$ layer (Model 2R7) has its upper and lower surfaces at depths of about 120 and $460 \mathrm{~m}$, respectively, thereby simulating the relatively isothermal section of the hole between these depths. A double layer model (4R14) has a high-conductivity region at the surface to a depth of about $100 \mathrm{~m}$, and another between

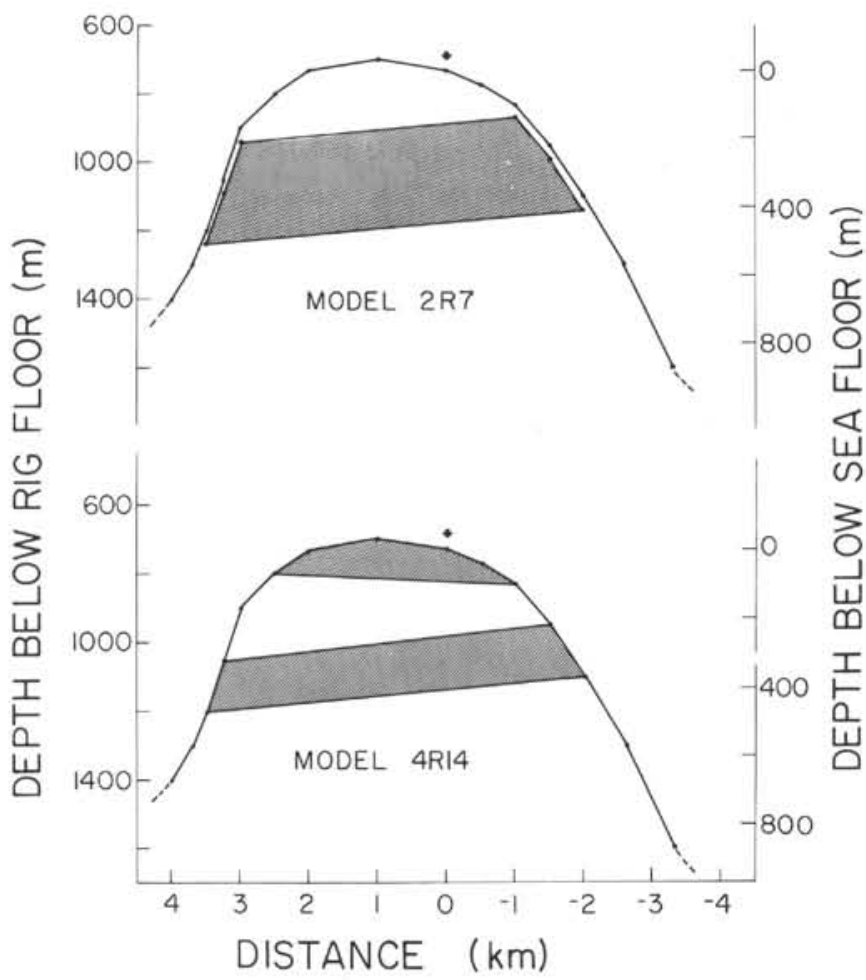

Figure 5. Upper section of 2-D finite-element models used to simulate the equilibrium thermal structure in Hole 735B. The cross-hatched regions are modeled with high thermal conductivity $\left(220 \mathrm{~W} \mathrm{~m}^{-1} \mathrm{~K}^{-1}\right)$, 100 times the regional value, to simulate zones of advection of pore water.

depths of about 230 and 460 mbsf at Hole 735B. The layer surfaces are not co-planar and somewhat tilted from horizontal because of the topography and uneven grid spacing in the models.

The double-layer model can be made to fit the equilibrium temperatures more closely than that of the single, high- $K$ layer, and additional layers might be included to match even more closely. Both single- and double-layer models were computed with a basal heat flux of $30 \mathrm{~mW} \mathrm{~m}^{-2}$, which may be somewhat high when compared to the equilibrium gradients in the lowermost part of Hole 735B. We did not explore the range of tradeoffs between the value of basal heat flux and the depths of the layer boundaries assigned. They are probably not tightly coupled, because the nearly isothermal temperatures of the high- $K$ layers are determined largely by the average temperature on their surfaces in contact with seawater.

Of course, we do not know whether the deepest equilibrium gradients deduced in the hole are representative of the deep heat flux. The deep gradient is certainly less than that which would result from heat flows of 140 to $160 \mathrm{~mW} \mathrm{~m}^{-2}$, the values expected from a seafloor site of this age (10 to 12 $\mathrm{Ma}$ ) on the basis of the heat flow vs. age relationship (Parsons and Sclater, 1977). This implies that considerable heat flux is missing at Site 735 , perhaps as a result of penetration of low-temperature seawater to depths of $>500$ mbsf, with advection of the heat to other locations.

In any case, these model results suggest that advection of seawater may occur in layers or regions of significant thickness beneath Site 735 to depths of at least several hundred meters. This indicates that the fluid permeability is relatively high in these layers, and that they must have 


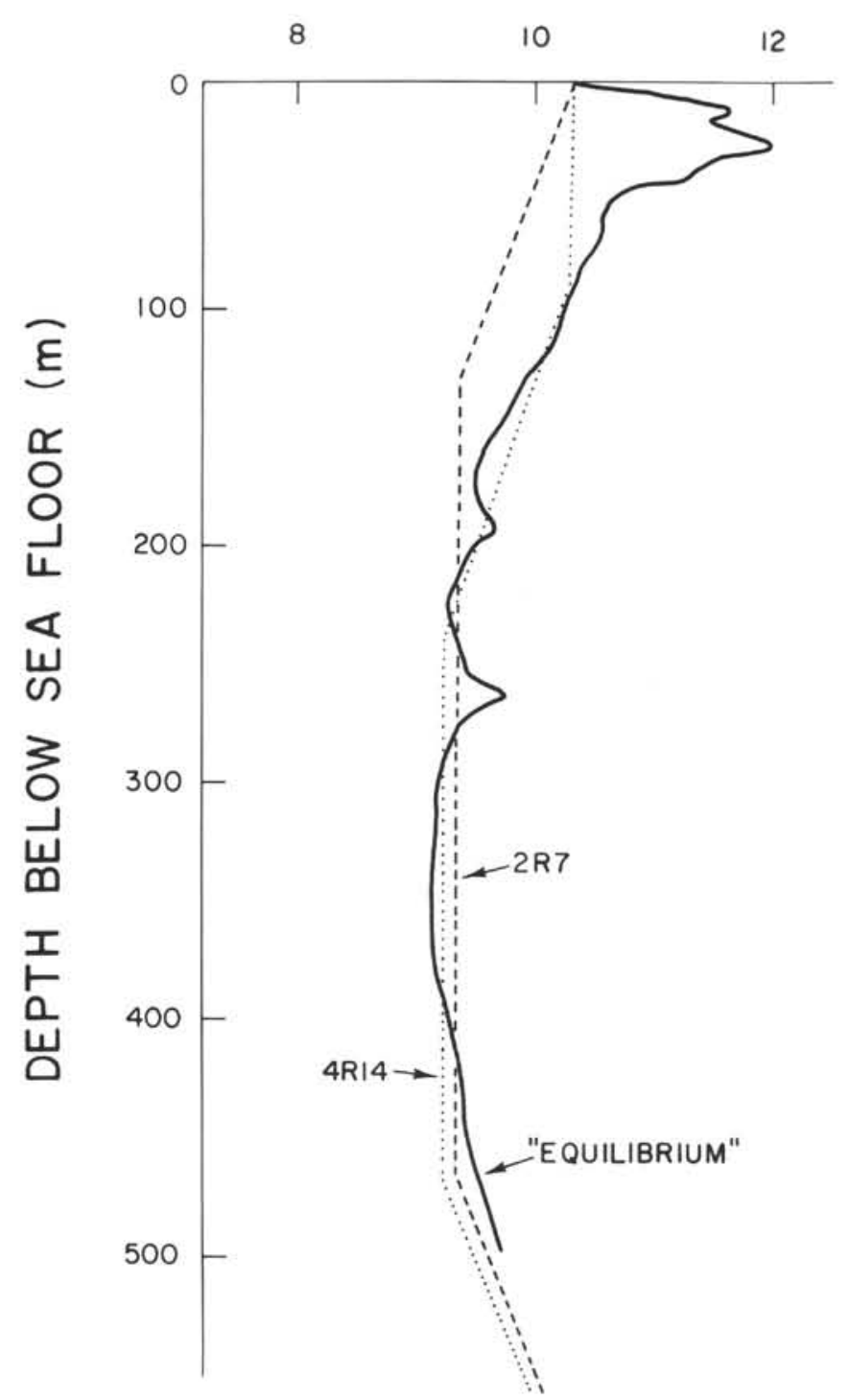

Figure 6. Temperature vs. depth profile for Hole 735B showing the equilibrium profile deduced from logging (solid curve) compared with those computed from 2-D models (Fig. 5, 2R7 dashed, 4R14 dotted). Basal heat fluxes of $30 \mathrm{~mW} \mathrm{~m} \mathrm{~m}^{-2}$ assumed for computed models.

dimensions significantly greater than the several relatively thin $(10-20 \mathrm{~m})$ layers with high porosity detected in standard logging.

The bulk fluid permeability was determined in situ over several depth ranges in Hole 735B by several packer measurements after drilling (Fig. 7). The average permeability in the uppermost $300 \mathrm{~m}$ of the hole is about $10^{-14} \mathrm{~m}^{2}$ and decreases below that depth by two orders of magnitude or more. The higher permeability in the upper $300 \mathrm{~m}$ may correspond to the high-conductivity layers in the models used to simulate the thermal structure in the hole (Fig. 5), although for lack of resolution the packer experiments cannot confirm the boundary depths of high-permeability layers. In addition, the bottom of the deepest high- $K$ layers in the thermal models may be deeper $(400 \mathrm{~m})$ than the $300-\mathrm{m}$ depth of the lower boundary of high permeability deduced from the packer experiments. Thus, the higher permeability and thermal model results appear generally consistent, but

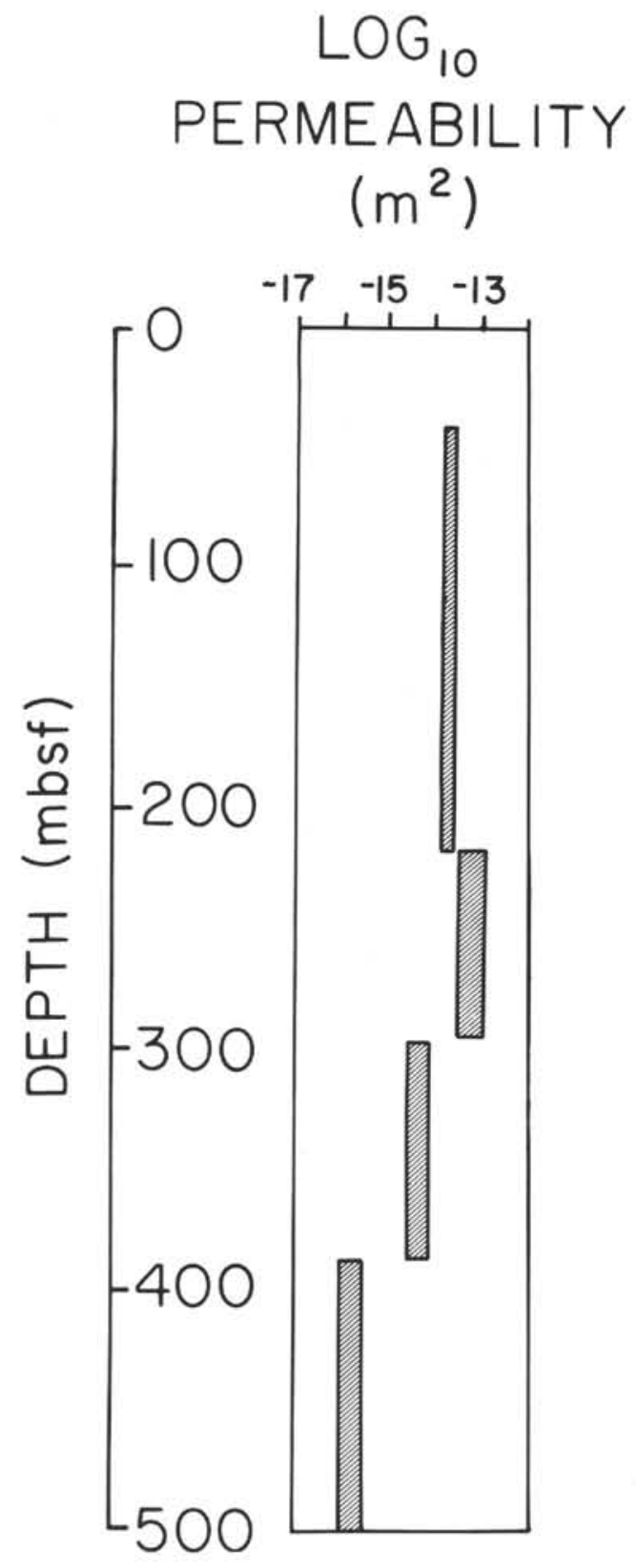

Figure 7. Vertical fluid permeability structure in Hole 735B determined from borehole packer experiments (K. Becker, this volume).

may have differences in detail that are presently unexplained.

\section{Model 2: One-Dimensional Conduction From Transient Boundary Temperatures}

Another type of model is suggested by the form of the overall equilibrium temperature vs. depth profile in Hole 735B. Although the gradient profile is complex in detail, the longest wavelength features include a maximum temperature at the surface that decreases with depth to a minimum at 300 to $350 \mathrm{mbsf}$, and then increases again to the bottom of the hole. In our discussion of the previous model, we noted that the local maxima at depths of about 30,190 , and 260 mbsf may be caused by advection of surface seawater into permeable 
zones as a result of pumping this fluid during drilling. We may also reasonably assume that the gradient above the local minimum at 170 mbsf has been similarly affected by the drilling because of the higher permeability there. Almost all advective disturbances associated with drilling the hole will warm it above equilibrium values because of the relatively warm water pumped from the sea surface.

Therefore, we can infer a smooth temperature vs. depth profile that passes through the surface equilibrium temperature (also the approximate water temperature, as deduced from nearby hydrographic data, Fig. 2) and through the two local minima at 170 and 220 mbsf (assumed not affected by advection), joining the calculated equilibrium profile at about 300 mbsf (Fig. 8). A purely conductive model to explain this type of profile is one of recent surface warming of the ocean waters, perhaps since the last glacial maximum about $10^{4} \mathrm{yr}$ ago. The warming would be gradually conducted downward, with the form of the temperature profile depending on the magnitude of the temperature shift, the time since warming, the thermal conductivity (diffusivity) of the rock, and the initial equilibrium temperature gradient.

To place reasonable bounds on the first of these parameters, we use the paleotemperature history of Indian Ocean waters inferred from paleontological evidence (CLIMAP, 1981). At the location of Site 735 , a warming of approximately $2^{\circ}$ to $4^{\circ} \mathrm{C}$ of surface ocean water may have occurred over the period from about 13 to $9 \mathrm{k}$.a. It is not clear to what depths such changes in surface water temperature might have ex-

\section{TEMPERATURE $\left({ }^{\circ} \mathrm{C}\right)$}

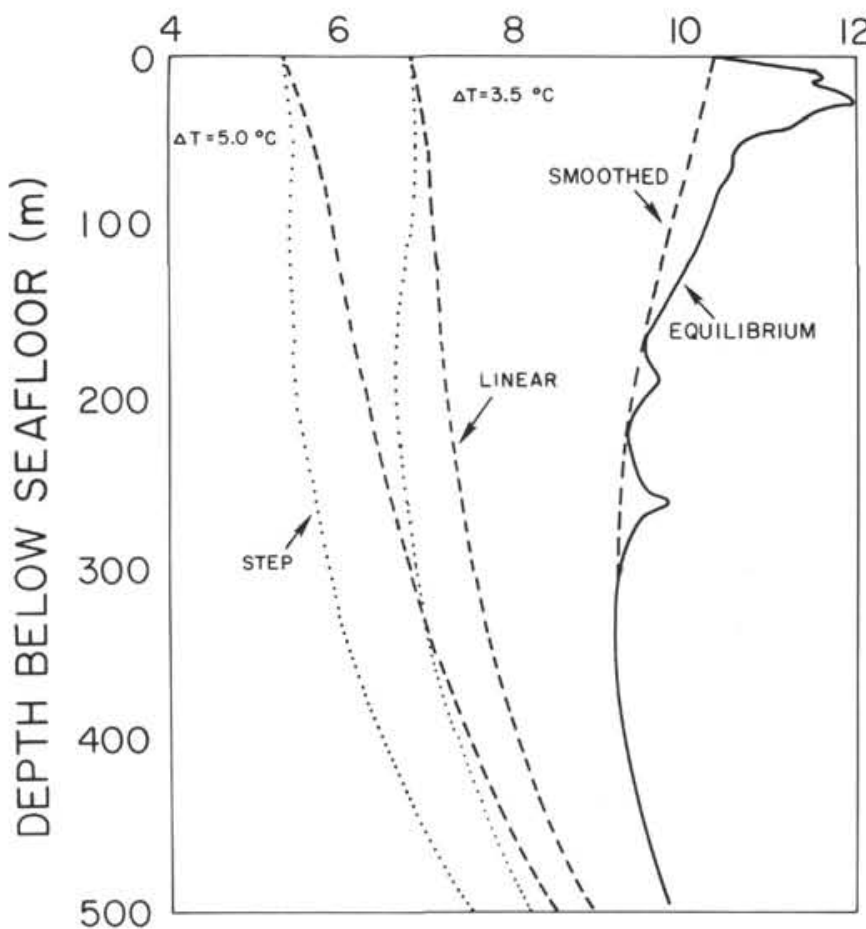

Figure 8. Temperature vs. depth profile in Hole 735B, with the solid curve the equilibrium profile calculated from the logs, smoothed as the dashed curve (see text). Dotted and light dashed curves are corrected profiles calculated on the basis of simple step or linear surface temperature changes, respectively, beginning $10^{4}$ years ago, with amplitudes of either $3.5^{\circ}$ or $5.0^{\circ} \mathrm{C}$ (see text). Uniform thermal diffusivity of $8 \times 10^{-7} \mathrm{~m}^{2} \mathrm{~s}^{-1}$ assumed. tended. Dynamically, it seems reasonable that climatic changes associated with glaciation might readily affect any well-mixed layer occurring above a deeper thermocline or pycnocline. However, we note (Fig. 2) that the mixed layer was less than $100 \mathrm{~m}$ thick in May 1984, whereas logging occurred in December 1987; there may be a seasonal variation in thermocline thickness at $32^{\circ} \mathrm{S}$ latitude, although the close correspondence between the ocean temperature profile and the logs measured $3.5 \mathrm{yr}$ later suggests only a small effect, if any. We are not aware of data to infer upper ocean dynamics in glacial time, but if the surface mixed layer were thicker (but colder), then the difference in temperature compared with that of today would probably be smaller at depth than that difference at the surface.

We consider one-dimensional models, which include either a step function or linear ramp increase of surface temperature at Site 735 , to bound the unknown time dependence of changes in water temperature since the last glacial cycle. Previous glacial cycles will be relatively unimportant because they occurred too long ago to have much effect on the present near-surface gradient. A simple analytical solution to the step function model is (Carslaw and Jaeger, 1959) as follows:

$$
T_{1}=T_{o} e r f c\left[Z / 2(\alpha t)^{1 / 2}\right],
$$

where $T_{o}=$ amplitude of temperature step,

$$
z=\text { depth, }
$$

$t=$ time since temperature step, and $e r f c=$ complementary error function.

Similarly, the solution to the linear temperature change is

$$
T_{2}=T_{o} 4 i^{2} e r f c\left[Z / 2(\alpha t)^{1 / 2}\right],
$$

where $T_{\mathrm{o}}$ is the total temperature change from time $t$ to the present, and $i^{2}$ erf $c=$ second integral of the complementary error function (Carslaw and Jaeger, 1959).

For initial calculations we used $T_{o}=3.5^{\circ} \mathrm{C}, t=10^{4} \mathrm{yr}$, for both models. The mean thermal conductivity of the mainly gabbro samples recovered during Leg 118 was $2.20 \mathrm{Wm}^{-1} \mathrm{~K}^{-1}$ \pm 0.22 (S.D.), and the thermal diffusivity, $\alpha(=K / \rho c$, where $\rho$ is density and $c$ is heat capacity), is estimated as about $8 \cdot 10^{-7}$ $\mathrm{m}^{2} \mathrm{~s}^{-1}$ (Kappelmeyer and Haenel, 1974). As expected (Fig. 8), the negative equilibrium gradient found in the upper part of the hole is greatly reduced (step function) or disappears (linear change). However, the low or negative gradients in the upper $200 \mathrm{~m}$ are still increasing systematically below that depth, indicating that the correction is not large enough. Therefore, we increased $T_{\mathrm{o}}$ to $5.0^{\circ} \mathrm{C}$, with the result (Fig. 8) that no negative gradients appear for either model, although the profile for the step function model is nearly isothermal for the upper $200 \mathrm{~m}$. The profile for the linear change model is $\mathrm{S}$-shaped, with the gradients still increasing significantly with depth.

These model results suggest (1) that the linear change model may fit better (more uniform gradient) than that for a step change, and (2) that the magnitude of the temperature change may be even greater than $5^{\circ} \mathrm{C}$. However, we did not attempt to refine the models further, because of the approximations made to smooth the equilibrium gradient and because larger temperature changes seem inconsistent with the paleotemperature evidence. The results show that the change of sign of the equilibrium gradient with depth can be removed with reasonable corrections for past changes in ocean-water temperature. It seems possible that the actual equilibrium 
gradient has been disturbed by both past temperature changes and advection of seawater into the rock, although the latter would dominate the former if advection were ubiquitous over the upper part of the section drilled at Hole 735B.

We note that the calculated gradient for the deepest $50 \mathrm{~m}$ of Hole $735 \mathrm{~B}$, in the case of the correction resulting in the most linear profile (linear temperature change, $5^{\circ} \mathrm{C}$ amplitude), is only slightly greater than $0.01^{\circ} \mathrm{C} \mathrm{m}^{-1}$, equivalent to a heat flow of about $25 \mathrm{~mW} \mathrm{~m}^{-2}$. Even though the gradient probably still increases with depth at Site 735 , so that we have not determined the equilibrium heat flux in Hole $735 \mathrm{~B}$, we think it unlikely that this gradient will exceed the deepest calculated value by a factor of 2 . That still would be a low value for the estimated 10 to $12 \mathrm{Ma}$ crust at Site 735 , suggesting that heat is removed by other mechanisms like advection of pore water, perhaps not surprising in view of this site's anomalous topographic and structural setting.

A general warming of ocean temperatures since the last glaciation should have an effect on the surface heat flux and temperature profiles at all affected locations. In reviewing all reliable DSDP geothermal data, Hyndman et al. (1987) did not observe any systematic effects with depth at sites in all major ocean basins. However, most sites have relatively few data, most commonly only one temperature measurement at depth, which would not be sufficient to detect nonequilibrium gradients. Only a few sites with temperatures measured at multiple depths extend deeper than 200 mbsf (only one in the Indian Ocean), a depth range over which nonlinearities in gradients as a result of warming since the last glacial stage $\sim 10^{4} \mathrm{yr}$ ago would be difficult to detect (Fig. 8). However, no negative gradients were measured at any site, and the drill-hole measurements did not give systematically different values of heat flow in comparison to oceanographic shallow-probe measurements. All water depths from DSDP sites were greater than those at Site $735(730 \mathrm{~m})$, although one was as shallow as 1200 $\mathrm{m}$, which suggests that any temperature changes in the deeper Indian Ocean are less than those inferred by our modeling at Site 735 . It seems intuitively reasonable that ocean temperature variations resulting from climate variations would be attenuated with depth in the oceans.

\section{CONCLUSIONS}

Thermal modeling of the 500 -m-deep equilibrium temperature profile calculated for Hole 735B leads to the following conclusions:

1. The reversal of equilibrium temperature gradient with depth at Site 735 cannot be explained by any geologically reasonable steady-state conduction models.

2. At least two different types of thermal models may explain the equilibrium temperature profile: (a) a steady-state, 2-D model having one or more zones of high permeability above $400 \mathrm{mbsf}$, allowing the surrounding seawater to percolate through the rock at rates sufficient to remove heat by advection; and (b) a transient, 1-D conduction model for the warming by $5^{\circ} \mathrm{C}$ or more of ocean waters at the depth $(730 \mathrm{~m}$ below sea level) and location of Site 735 since the last glaciation $\left(10^{4} \mathrm{yr}\right.$ ago $)$. The low heat flow $\left(<30 \mathrm{~mW} \mathrm{~m}^{-2}\right)$ found for the deepest part of Hole 735B implies that up to $80 \%$ of the cooling is by advection of pore water extending to depths $>500$ mbsf.

3. The relative importance of these or other, possibly more complex, models for producing the unusual equilibrium gradient cannot be determined without more detailed borehole data (especially permeability zonation) or additional information from other disciplines (especially ocean paleotemperatures) relevant to this problem.

\section{ACKNOWLEDGMENTS}

We thank T-C. Lee (University of California, Riverside) for the computer code used in the 2-D modeling. L. Keigwin helped to steer us in the right direction to evaluate paleotemperatures in the Indian Ocean. G. Heimerdinger obtained ocean temperature data for us, and L. Angeloni drafted the figures. K. Becker provided useful comments about the manuscript, and M. Langseth suggested several useful improvements in a review. RVH acknowledges partial support from USSAC (JOI, Inc.) and the Woods Hole Oceanographic Institution in preparation of this study. This is contribution No. 7338 of the Woods Hole Oceanographic Institution.

\section{REFERENCES}

Bonatti, E., and Hamlyn, P. R., 1980. Oceanic ultramafic rocks. In Emiliani, C. (Ed.), The Sea, Vol. 7: New York (Wiley and Sons), 241-283.

Bullard, E. C., 1947. The time necessary for a bore hole to attain temperature equilibrium. R. Astron. Soc., Geophys. Suppl., 5:127-130.

Carslaw, H. S., and Jaeger, J. C., 1959. Conduction of Heat in Solids, 2nd Ed: Oxford (Clarendon Press).

CLIMAP, 1981. Seasonal reconstructions of the Earth's surface at the last glacial maximum. Geol. Soc. Am. Map and Chart Ser., MC-36:Map 5.

Cormier, M-H., Detrick, R. S., and Purdy, G. M., 1984. Anomalously thin crust in oceanic fracture zones: new seismic constraints from the Kane fracture zone, J. Geophys. Res., 89:10249-10266.

Hyndman, R. D., Langseth, M. G., and Von Herzen, R. P., 1987. Deep Sea Drilling Project geothermal measurements: a review. Rev. Geophys., 25:1563-1582.

Kappelmeyer, O., and Haenel, R., 1974. Geothermics, Geoexploration Monogr. Ser. 1, No. 4: Berlin (Gebruder Borntraeger), 208-215.

Lee, T-C., and Henyey, T. L., 1974. Heat-flow refraction across dissimilar media. Geophys. J. R. Astron. Soc., 39:319-333.

Parsons, B., and Sclater, J. G., 1977. An analysis of the variation of ocean floor bathymetry and heat flow with age. J. Geophys. Res., 82:803-827.

Shipboard Scientific Party, 1989. Site 735. In Robinson, P. T., Von Herzen, R., et al., Proc. ODP, Init. Repts., 118: College Station, TX (Ocean Drilling Program), 89-212.

Date of initial receipt: 22 August 1989

Date of acceptance: 5 April 1990

Ms 118B-139 